\title{
Oral Rehabilitation of a Severe Early Childhood Caries Case with Prosthetic Intervention: A 12-Month Follow-up
}

\author{
Shagun Agarwal ${ }^{1}$, Saumya Navit ${ }^{2}$, Suleman A Khan ${ }^{3}$, Seema Jabeen ${ }^{4}$, Nishi Grover ${ }^{5}$
}

\begin{abstract}
Early childhood caries (ECC) is a rapid form of dental caries. It is the most common chronic childhood disease that can compromise a child's self-esteem, nutritional intake, oral development, and quality of life subsequently leading to malocclusion and psychological problems. Presence of poor oral hygiene, frequent use of sweetened beverages, and presence of high levels of Streptococcus mutans are some of the causative factors for this multifactorial disease. Management of these severely un-restorable primary teeth in children still remains a challenge to pediatric dentists all over the world. This case report presents the rehabilitation of $5 \frac{1}{2}$-year-old boy with severe early childhood caries (S-ECC) with 12 months follow-up for the same.
\end{abstract}

Keywords: Dental caries, Diet, Prevention, Prosthetic rehabilitation, Severe early childhood caries.

Journal of South Asian Association of Pediatric Dentistry (2020): 10.5005/jp-journals-10077-3041

\section{INTRODUCTION}

Severe early childhood caries (S-ECC) is a virulent form of dental caries associated with pain, infection, premature loss of primary dentition in toddlers and preschool children generally common among low-socioeconomic groups and in general population. ${ }^{1}$ Severe early childhood caries does not only affect the teeth but also has a widespread impact on children health. The definition of S-ECC is any sign of smooth surface caries in a child younger than 3 years of age, and from ages 3 to 5 years, one or more cavitated, missing (due to caries) or filled smooth surfaces in primary maxillary anterior teeth or a decayed, missing, or filled score of $\geq 4$ (age 3 ), or $\geq 5$ (age 4 ), or $\geq 6$ (age 5 ) surfaces constitutes S-ECC. ${ }^{1}$ Mostly S-ECC affects primary maxillary incisors, followed by primary first molars. The esthetic restoration of these mutilated teeth since a long time has been a challenge to the pediatric dentists worldwide due to the widespread destruction of tooth structure, large exposure of pulp chambers also leaving minimal surface for bonding. Hence, extraction is indicated as a treatment plan for such affected primary teeth. ${ }^{2}$ When extraction of such primary teeth is required, many parents seek an esthetic solution to replace the lost teeth. Early loss of teeth can also be quite psychologically disturbing to the young child especially when he views himself as being different from his peers. Anterior dental disharmonies can interfere with normal tongue placement which then can lead to the development of maladaptive articulatory habits. ${ }^{3}$ This case report describes the management of $51 / 2$-year-old boy presenting with S-ECC with a 12 months follow-up.

\section{Case Description}

A $5 \frac{1}{2} 2$-year-old boy reported with the chief complain of difficulty in chewing and unpleasant smile due to multiple decayed teeth. Medical history was nonsignificant. The boy was very anxious during his first visit to the department. Parents were asked to assess his full diet for 1 week of time. His dietary evaluation revealed he was on high cariogenic diet with sweet score of 20. Since patient sweet score was in the watch out zone, parents were given dietary counseling, and diet modification methods were informed to them.

\begin{abstract}
${ }^{1-5}$ Department of Pedodontics and Preventive Dentistry, Saraswati Dental College and Hospital, Lucknow, Uttar Pradesh, India

Corresponding Author: Shagun Agarwal, Department of Pedodontics and Preventive Dentistry, Saraswati Dental College and Hospital, Lucknow, Uttar Pradesh, India, Phone: +91 8707753716, e-mail: shagungrwl@gmail.com
\end{abstract}

How to cite this article: Agarwal S, Navit S, Khan SA, et al. Oral Rehabilitation of a Severe Early Childhood Caries Case with Prosthetic Intervention: A 12-Month Follow-up. J South Asian Assoc Pediatr Dent 2020;3(1):39-43.

Source of support: Nil

Conflict of interest: None

Intraoral examination revealed multiple carious teeth involving maxillary and mandibular $(55,63,65,73,74,83,84)$ with multiple missing teeth in both the arches $(51,52,53,54,61,62,64$, $71,72,75,81,82,85$ ) (Figs 1 to 3). Due to uncooperative behavior of the child preoperative radiographs could not be taken. On the basis of clinical findings, diagnosis was made as S-ECC.

During the first visit, behavior modification was done for the child using modeling and tell-show-do techniques. Parents were also counseled to reduce the consumption of cariogenic and sweetened food stuffs. Fluoride gel [acidulated phosphate fluoride gel (APF): 1.23\%] was applied topically on all decayed teeth to reduce the caries progression. The entire treatment plan for restorative rehabilitation was explained to the parents, the treatment was divided into multiple visits, and informed consent for the same was obtained from the parents. Parents were explained about the importance of doing their child treatment in multiple visits along with the importance of various recall follow-up visits. The mother was instructed to follow oral hygiene measures and also to supplement cariogenic food with noncariogenic food items like cheese and peanuts.

For esthetic rehabilitation of the child, parents were given the choice of removable dentures and fixed functional space maintainers, advantages and disadvantages for each of them was

(c) The Author(s). 2020 Open Access This article is distributed under the terms of the Creative Commons Attribution 4.0 International License (https://creativecommons. org/licenses/by-nc/4.0/), which permits unrestricted use, distribution, and non-commercial reproduction in any medium, provided you give appropriate credit to the original author(s) and the source, provide a link to the Creative Commons license, and indicate if changes were made. The Creative Commons Public Domain Dedication waiver (http://creativecommons.org/publicdomain/zero/1.0/) applies to the data made available in this article, unless otherwise stated. 


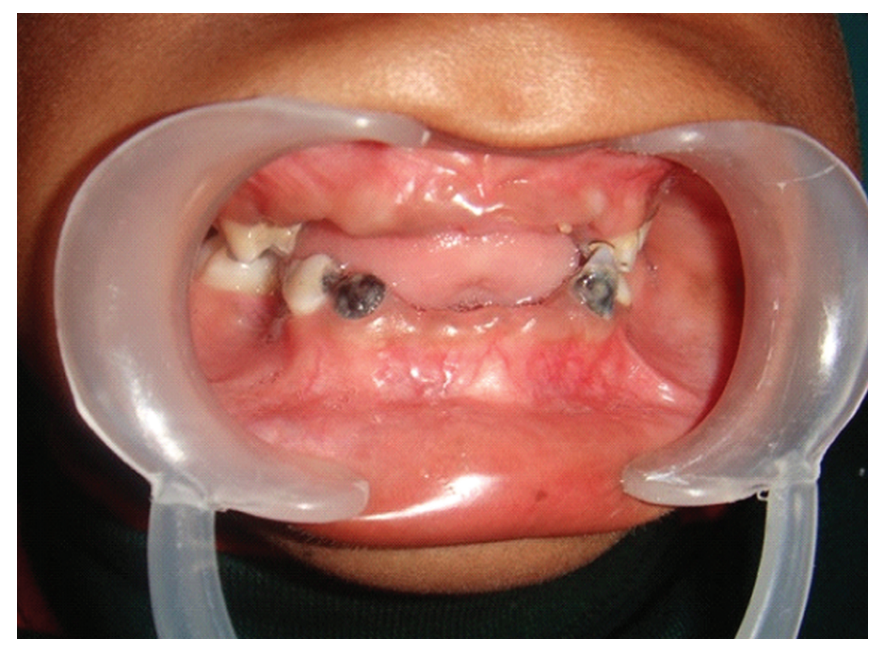

Fig. 1: Preoperative clinical image of the patient

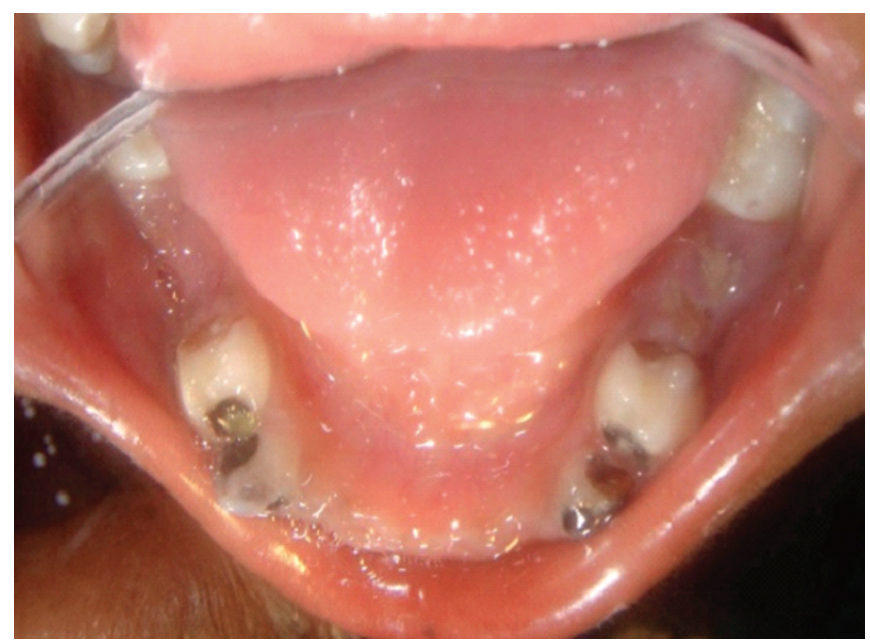

Fig. 3: Preoperative clinical image of mandibular arch

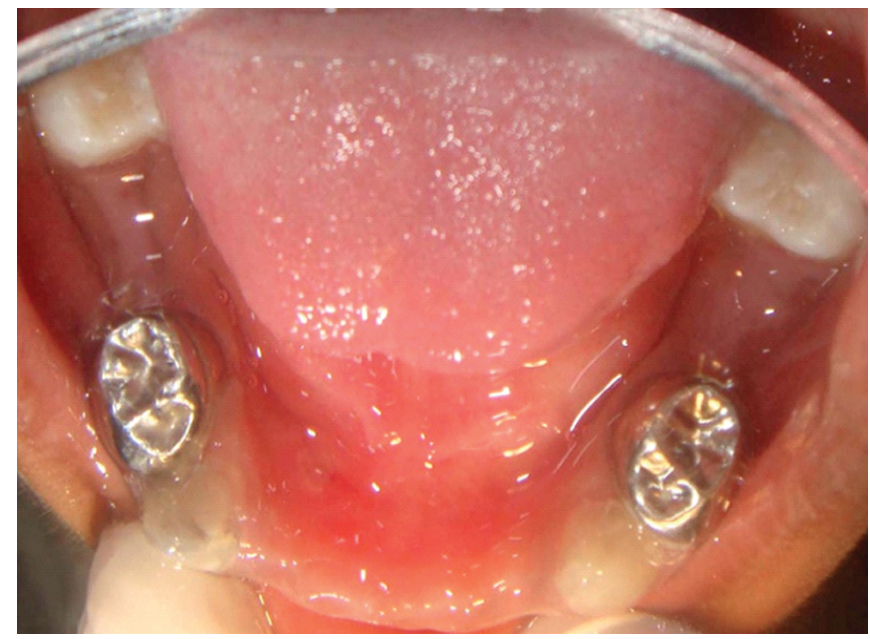

Fig. 5: Stainless steel crowns in respect to 74,84 in mandibular arch after pulp therapy

explained in detail to the parents, in which they chose removable dentures in the initial phase, so the treatment was planned accordingly, and the importance of follow-up visits was also

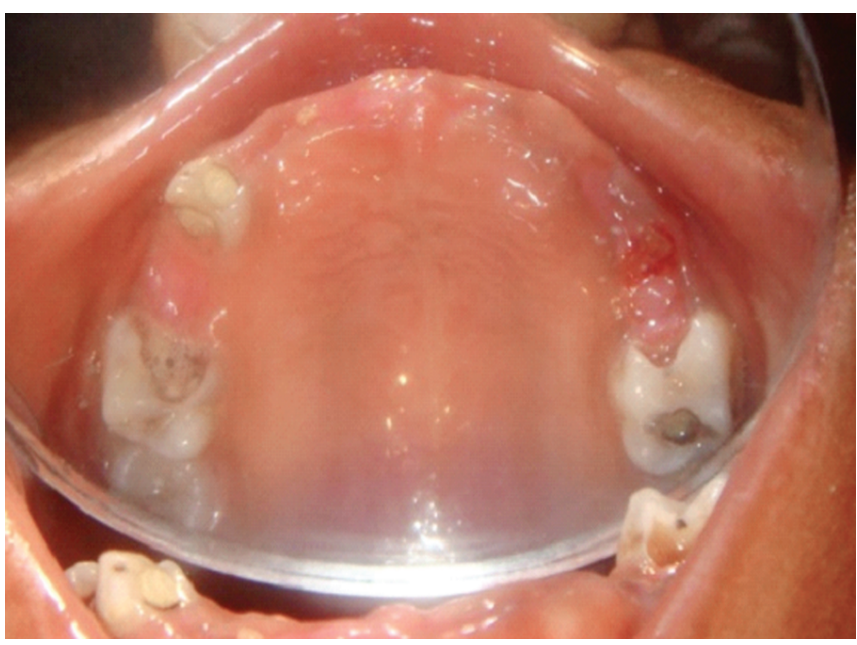

Fig. 2: Preoperative clinical image of the maxillary arch

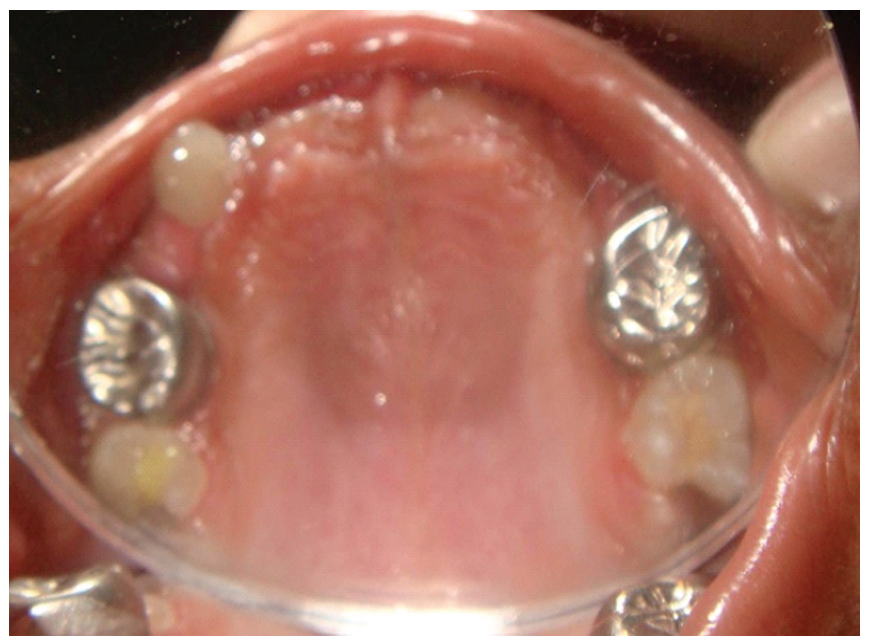

Fig. 4: Stainless steel crowns given in respect to 55, 65 in maxillary arch after pulp therapy

explained to them. The importance of fixed space maintainers once permanent teeth start erupting was explained in detail to the parents to avoid any future malocclusion. Treatment was started after obtaining their consent.

During the second visit, dentin stabilization/temporization was done for all the molars to reduce their caries progression.

On the third visit for all endodontically involved carious molars under local anesthesia, pulp therapy followed by stainless steel crown restorations was done in both maxillary and mandibular arches (Figs 4 and 5). A postoperative orthopantomogram (OPG) was taken in his fourth visit (Fig. 6).

During his fifth visit, maxillary and mandibular arches' primary impression was done with alginate impression material followed by fabrication of custom tray with definitive border molding was done. The secondary impression was taken with light body of rubber base impression material, and a master cast was prepared. Occlusal rims were fabricated on the working cast and were inserted in the patient's mouth to establish vertical dimension and centric relation (Fig. 7). The vertical dimension was first determined by swallowing, checked by the rest position and associated freeway 


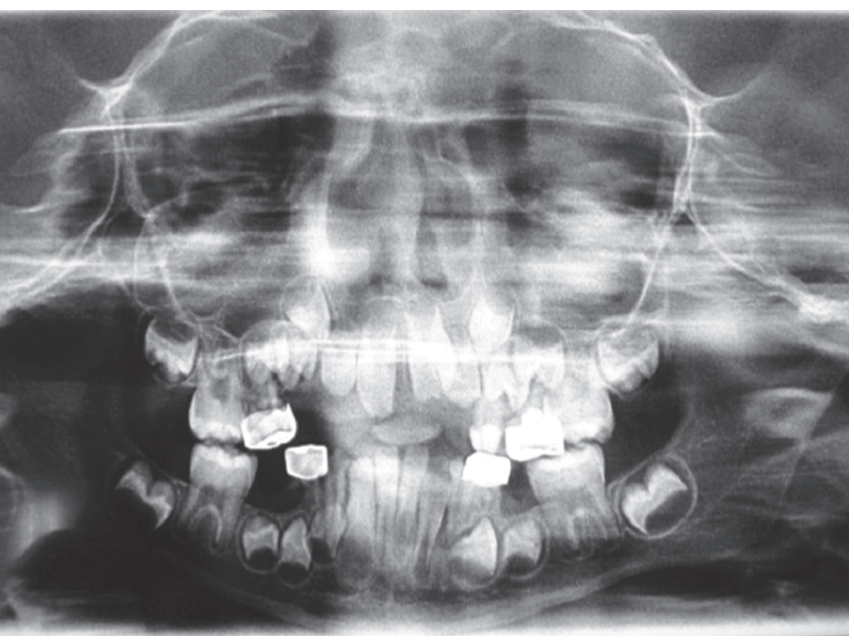

Fig. 6: Postoperative orthopantomograph

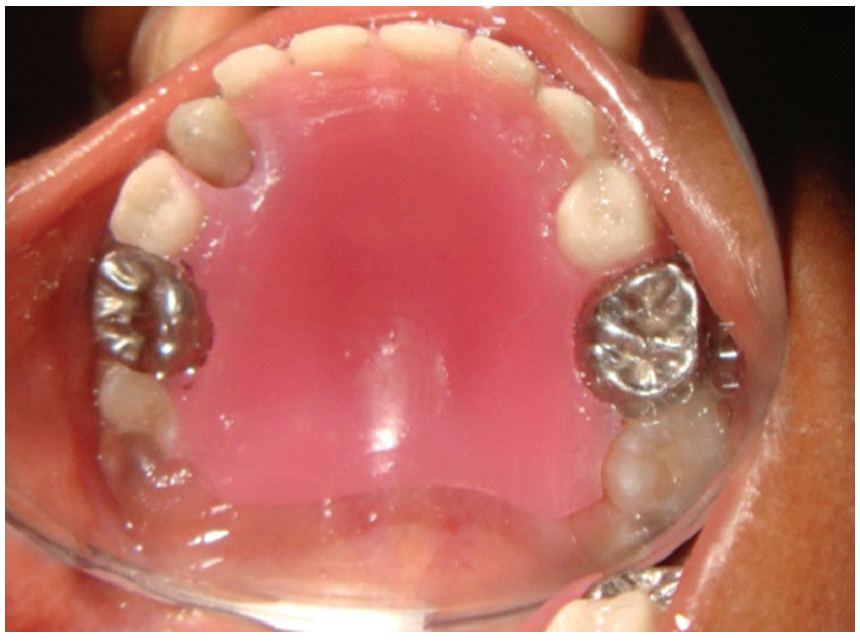

Fig. 8: Acrylic removable partial denture given in respect to maxillary arch

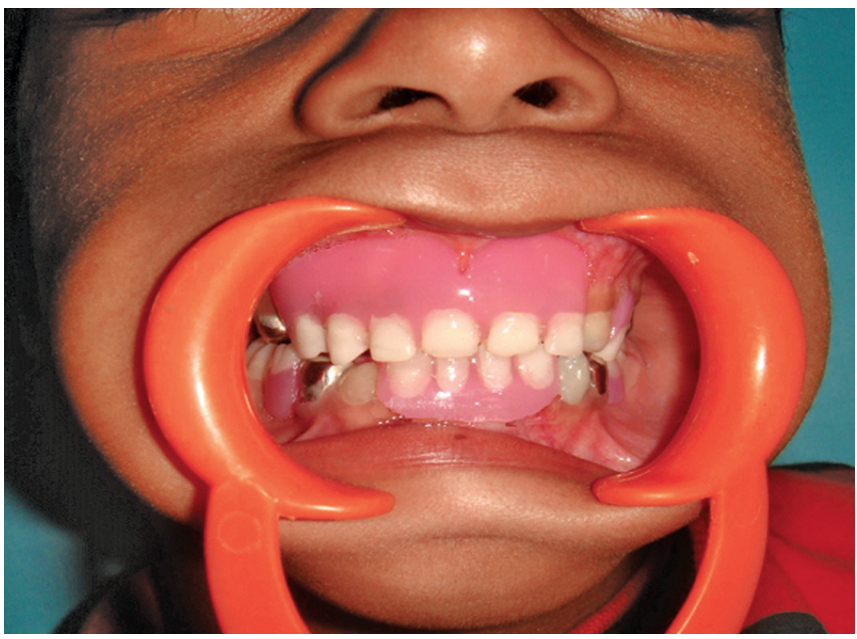

Fig. 10: Occlusion after delivery of both the dentures postoperatively

space, and thereafter verified by means of phonetics leading to registration of centric relation.

The upper and lower dentures were processed with a conventional type resin inserted, and the appropriate adjustments

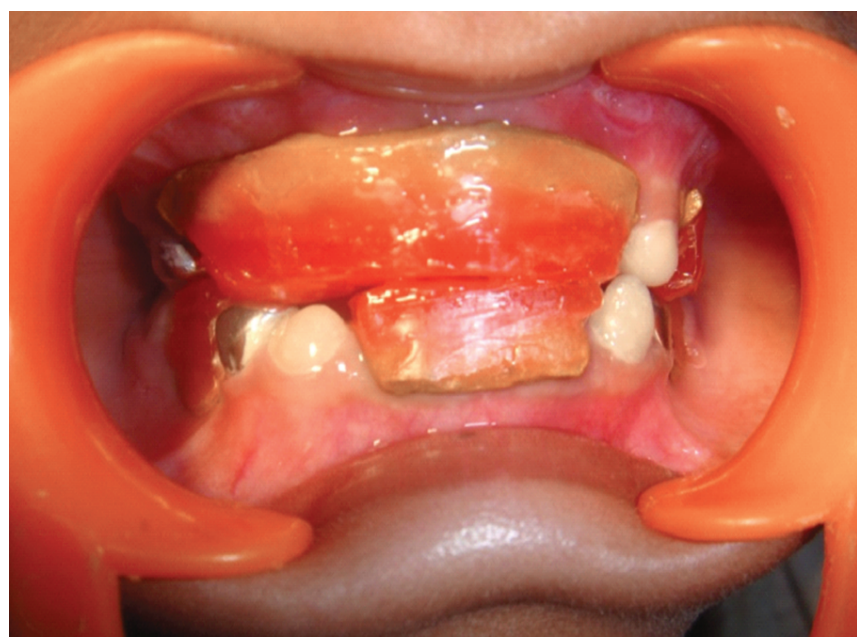

Fig. 7: Occlusal bite registration done

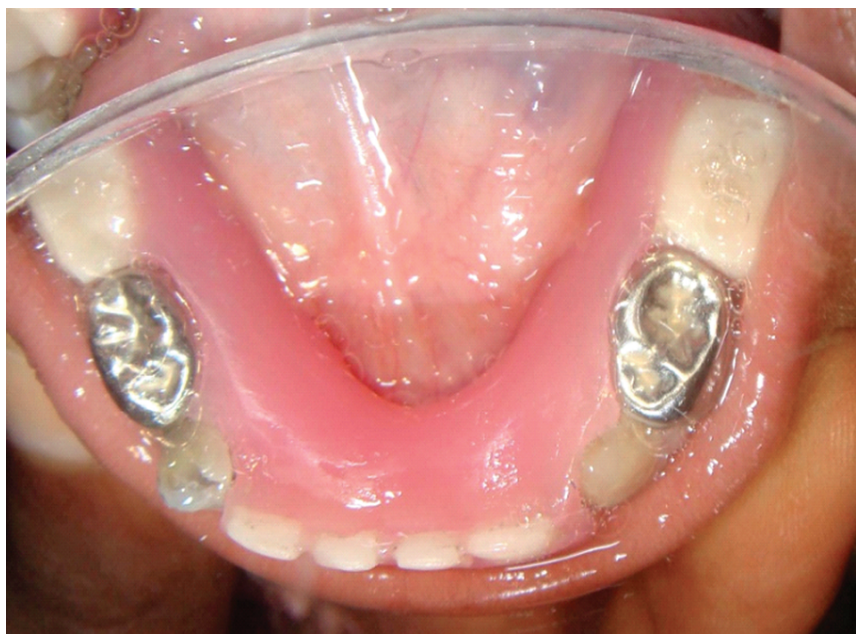

Fig. 9: Acrylic removable partial denture in respect to mandibular arch

were also carried out (Figs 8 to 10). Patient was recalled next day.

On his sixth visit appointment, his discomfort was relieved, and parents were given verbal and written instructions for denture care and oral hygiene maintenance and were instructed for periodic follow-up every month. During periodic follow-up visits after 9 months, dentures were relieved in the areas of erupting teeth, and periodic relining was done following adjustments made for the erupting teeth (Fig. 11).

After 12 months of follow-up, permanent central incisors were seen erupting in both maxillary and mandibular aches (Figs 12 and 13), and hence, dentures were now replaced with fixed space maintainers, nance palatal arch was placed for bilaterally lost maxillary deciduous teeth and lingual holding arch was placed for bilaterally lost mandibular molars teeth (Figs 14 and 15). The case is under regular follow-up for eruption of permanent teeth in normal occlusion.

\section{Discussion}

Tooth decay in infants and babies is now collectively known as early childhood caries (ECC). Though the cause of ECC is same as smooth surface caries, the bacterial flora and host defense system 


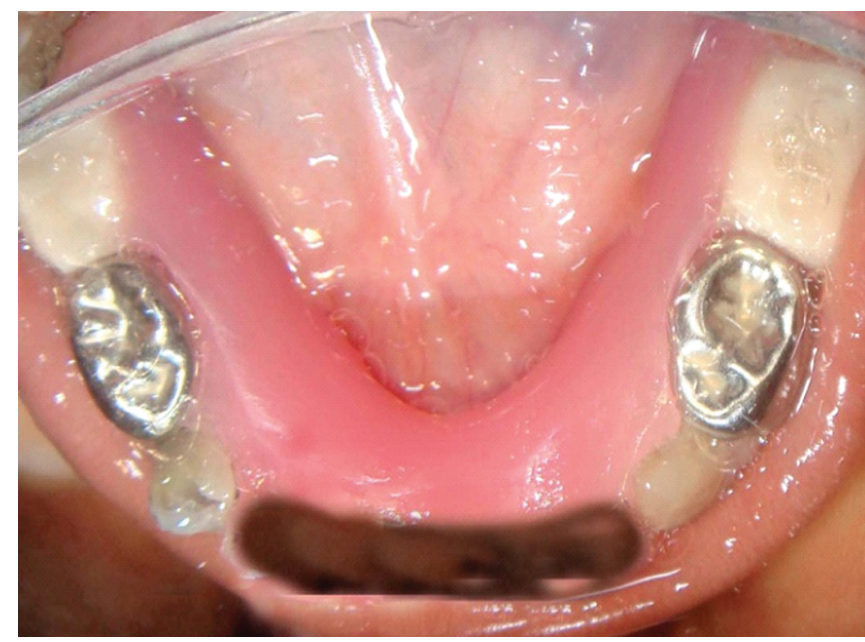

Fig. 11: Dentures were relieved in the areas of erupting teeth after 9 months

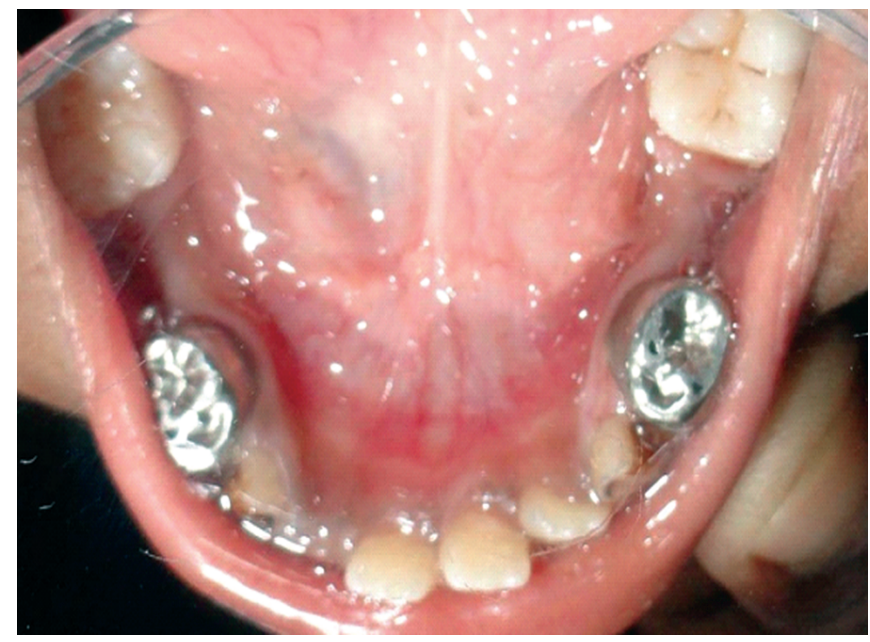

Fig. 13: Erupting permanent incisors in mandibular arch after 12 months

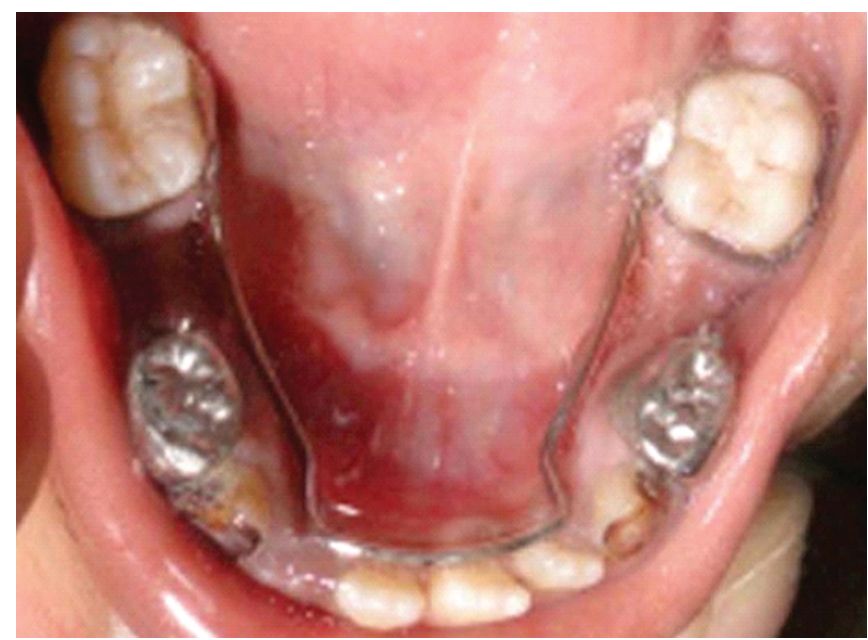

Fig. 15: Lingual holding arch placed for mandibular arch

in young infant are in the process of being established, also since tooth surfaces are newly erupted, they show hypoplastic defects. High rate of fermentable carbohydrates intake with

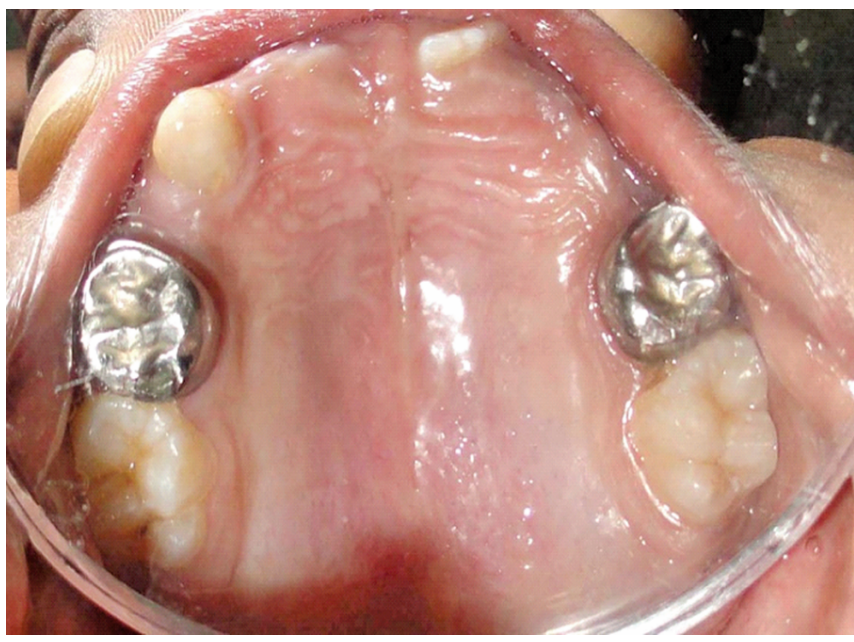

Fig. 12: Erupting permanent incisors in maxillary arch after 12 months

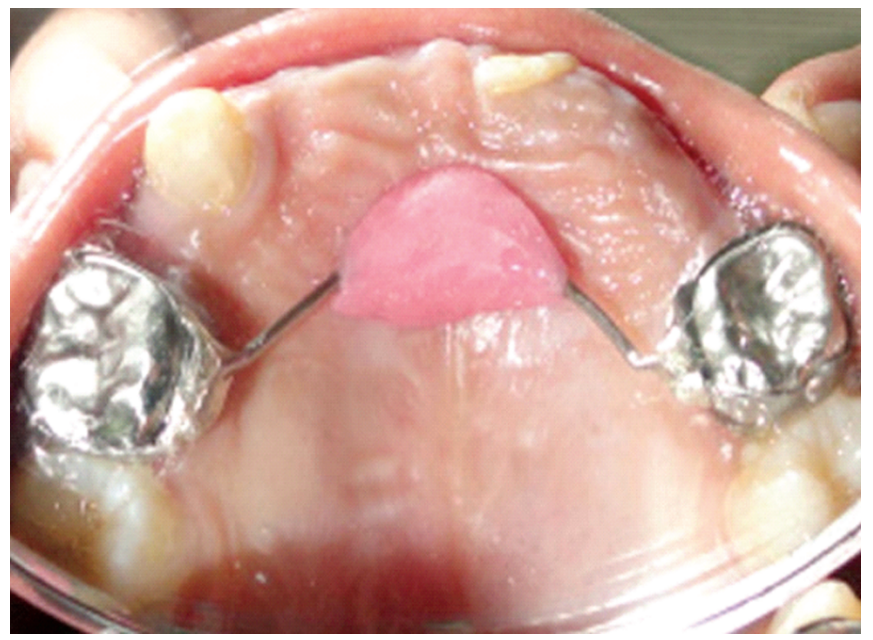

Fig. 14: Nance palatal arch placed for space maintenance in maxillary arch

enamel hypoplasia in young infants leads to ECC. Early loss of primary teeth affects both psychological and physiological state of a patient during his growing years. ${ }^{3}$ A very high failure rate is observed while restoring these severely decayed primary anterior teeth because of the absence of tooth structure and poor adhesion of bonding agents to primary teeth. Also these children are among the youngest and least manageable group of patients. In young infants, this multifactorial disease is especially associated with the frequent use of sweetened fluids and fermentable carbohydrates over extended periods, poor oral hygiene, as well as high level of mutans streptococci infection. ${ }^{3}$ Early screening for signs of caries development, starting from the first tooth eruption could identify babies with high risk of ECC, and such children should be targeted with professional preventive program which includes fluoride varnish application, fluoride dentifrices, sealants, diet counseling, and chlorhexidine and xylitol pacifiers. Professional treatment for ECC ranges from diet counseling to the prosthetic rehabilitation of the patient. Restorations are accomplished by glass ionomer cement (GIC), composites, pulp therapy, followed by crowns, while grossly decayed teeth can be extracted followed by space maintainers. ${ }^{3,4}$ 
Rifkin et al. ${ }^{4}$ described restoring primary anterior teeth with post and crown, but it was not widely accepted because of the potential for interference with physiological root resorption. The wire which extends a long way into the root also can increase internal stresses within the root leading to root fracture sometimes. Motisuki et al. ${ }^{5}$ have restored severely decayed primary teeth using an indirect composite resin restoration using fiber glass post. Although this technique was expensive and required extensive laboratory work, the restoration of occlusion and space maintenance by the fabrication of a prosthetic restoration enables better speech and improvement in their health and nutritional status. ${ }^{6}$ Also in addition to this, prosthetic dentures help in increased vertical dimension which helps to establish better muscle tone and also lip support. In the present case, space maintainers were given after 12 months of follow-up to avoid space loss problems. Stainless steel crowns were chosen due to their ability to accurately resemble the anatomy of primary molars, also to successfully restore occlusion and to provide adequate food grinding. Due to the patients high caries risk, the smoothness of the crown contributes to reduction in bacterial biofilm accumulation, favoring better oral hygiene. ${ }^{7}$ The choice of removable dentures is mostly employed when anterior teeth are prematurely lost. Unfortunately, there are number of drawbacks associated with this use, like dependency on the patient for the success, child may not wear it, accidental ingestion or aspiration, breakage, and loss. Besides, a removable appliance may have a deleterious effect on the involved soft tissues and periodontal tissues. Hence, the efficiency and effectiveness of the space maintenance can be compromised. ${ }^{8}$

Patil et al. ${ }^{9}$ affirmed that the fixed space maintainers used to replace deciduous central incisors have a good success rate with improving esthetics and functions involving less patient cooperation with less irritation to the oral tissues. In the present case, due to multiple missing teeth, removable upper and lower dentures were given, and the patient with his parents was very satisfied with the final results. In the first follow-up visit, the facial expression of the patient was remarkable, and the change in his self-esteem was evident. The parents related no difficulty in denture maintenance, and the child adopted very well with them during both eating and speaking. A disease-free mouth brings happiness and satisfaction not only to the parents and children but also to the dental team who provided the information, instruction, and reinforcement. ${ }^{10} \mathrm{~A}$ complete cooperation from the patient and parent contributed to the success of the treatment.

\section{Conclusion}

Severe early childhood caries is a multifactorial disease that has numerous biological, psychosocial, and behavioral risk factors. Although ECC can be arrested, early detection is of paramount importance. A complete oral rehabilitation in S-ECC helps in relief of pain, improvement in speech, masticatory efficiency, esthetics, and psychological benefits. Treatment of S-ECC can be accomplished through different types of intervention, depending on the progression of the disease, the child's age, as well as the social, behavioral, and medical history of the child. Also, a closer cooperation between health-care professionals and pediatric dentists is required today to control this rapidly spreading condition.

\section{References}

1. Gurusamy K, Raju OS, Krishna TP, et al. Oral rehabilitation of an S-ECC case with orthodontic intervention: 18 months follow up. Int J Clin Pedia Dent 2011;4(2):153-157. DOI: 10.5005/jp-journals-10005-1101.

2. Mishra A, Pandey R, Pandey N, et al. A pedoprosthetic rehabilitation in patients with severe early childhood caries (S-ECC). BMJ Case Rep 2013( 2013):1-3. DOI: 10.1136/bcr-2013-010269.

3. Parisotto TM, de Souza-E-Silva CM, Steiner-Oliveira C, et al. Prosthetic rehabilitation in a four-year-old child with severe early childhood caries: A case report. J Contemp Dent Pract 2009;10(2):90-97. DOI: 10.5005/jcdp-10-2-90.

4. Rifkin A. Composite post crowns in anterior teeth. J Dent Assoc S Afr 1983;38(4):225-227.

5. Motisuki C, Santos-Pinto L, Giro EM. Restoration of severely decayed primary incisors using indirect composite resin restoration technique. Int J Pediatr Dent 2005;15(4):282-286. DOI: 10.1111/j.1365263X.2005.00645.x.

6. Muthu MS, Shivkumar N. Pediatric Dentistry: Principals and practice, ch. 18, Early childhood caries, India: Elsevier India; 2009. pp. 209-218.

7. McDonald RE, Avery DR, Stookey GK. Dentistry for the child and adolescent 8th ed., ch. 10 Dental caries in the child and adolescent US: Elsevier Mosby Publication; 2004. pp. 205-235.

8. Wyne AH. Early childhood caries: nomenclature and case definition. Community Dent Oral Epidemiol 1999;27(5):313-315. DOI: 10.1111/ j.1600-0528.1999.tb02026.x.

9. Patil RB, Rachappa MM. A simple modification of fixed space maintainers for replacement of an avulsed maxillary primary central incisor. Int J Dental Clin 2011;2013:117.

10. Nizel AE. Dietary counseling for the prevention and control of dental caries. In: Nutrition. ch. 17, New Delhi, India: Jaypee Brothers Medical Publishers; 1989. pp. 277-292. 